\title{
Effect of sodium hexametaphosphate concentration and cooking time on the physicochemical properties of pasteurized process cheese
}

\author{
N. Shirashoji, ${ }^{*} \dagger$ J. J. Jaeggi, $\ddagger$ and J. A. Lucey ${ }^{1}$ \\ *Food Research and Development Laboratory, Morinaga Milk Industry Co. Ltd., Zama, Kanagawa 228-8583 Japan \\ †Department of Food Science, University of Wisconsin, Madison 53705-1565 \\ ¥Wisconsin Center for Dairy Research, Madison 53705-1565
}

\section{ABSTRACT}

Sodium hexametaphosphate (SHMP) is commonly used as an emulsifying salt (ES) in process cheese, although rarely as the sole ES. It appears that no published studies exist on the effect of SHMP concentration on the properties of process cheese when $\mathrm{pH}$ is kept constant; $\mathrm{pH}$ is well known to affect process cheese functionality. The detailed interactions between the added phosphate, casein $(\mathrm{CN})$, and indigenous $\mathrm{Ca}$ phosphate are poorly understood. We studied the effect of the concentration of SHMP $(0.25-2.75 \%)$ and holding time $(0-20 \mathrm{~min})$ on the textural and rheological properties of pasteurized process Cheddar cheese using a central composite rotatable design. All cheeses were adjusted to $\mathrm{pH}$ 5.6. The meltability of process cheese (as indicated by the decrease in loss tangent parameter from small amplitude oscillatory rheology, degree of flow, and melt area from the Schreiber test) decreased with an increase in the concentration of SHMP. Holding time also led to a slight reduction in meltability. Hardness of process cheese increased as the concentration of SHMP increased. Acid-base titration curves indicated that the buffering peak at $\mathrm{pH} 4.8$, which is attributable to residual colloidal Ca phosphate, was shifted to lower $\mathrm{pH}$ values with increasing concentration of SHMP. The insoluble Ca and total and insoluble P contents increased as concentration of SHMP increased. The proportion of insoluble $\mathrm{P}$ as a percentage of total (indigenous and added) $\mathrm{P}$ decreased with an increase in ES concentration because of some of the (added) SHMP formed soluble salts. The results of this study suggest that SHMP chelated the residual colloidal Ca phosphate content and dispersed CN; the newly formed Ca-phosphate complex remained trapped within the process cheese matrix, probably by cross-linking CN. Increasing the concentration of SHMP helped to improve fat emulsification and $\mathrm{CN}$ dispersion during

\footnotetext{
Received November 30, 2009.

Accepted March 29, 2010.

${ }^{1}$ Corresponding author: jalucey@facstaff.wisc.edu
}

cooking, both of which probably helped to reinforce the structure of process cheese.

Key words: pasteurized process Cheddar cheese, emulsifying salt, rheology, texture

\section{INTRODUCTION}

Process cheese is made by grinding natural cheese and then heating the cheese in the presence of one or more Ca chelating salts (phosphate or citrates), often called emulsifying salts (ES). In the United States, the Code of Federal Regulations (Department of Health and $\mathrm{Hu}-$ man Services, 2004) identifies 13 types of ES that can be used in process cheese manufacture, either singly or in combination, and allows for the addition of up to $3 \%$ (wt/wt; Kapoor and Metzger, 2008). These ES help disperse the insoluble $\mathrm{CN}$ in natural cheese curd, and it is these solubilized $\mathrm{CN}$ that can then act as emulsifiers around the liquid fat released during the heating and shearing of natural cheese. These ES function as ion exchangers, buffers, and Ca sequestrants and cause CN dispersion and peptization. Several reviews exist on the properties of the ES used for process cheese manufacture (Carić et al., 1985; Berger et al., 1998; Zehren and Nusbaum, 2000; Guinee et al., 2004).

Long-chain polyphosphates are commonly (but incorrectly) called hexametaphosphates. The real hexametaphosphates are ring forming and are not used in process cheese. Sodium hexametaphosphates (SHMP) have a wide range of uses in the food industry, including increasing the water binding properties of proteins in processed meats, protein precipitation for purification purposes, and prevention of protein sedimentation in sterilized milks (Molins, 1991). Sodium hexametaphosphates are often used in process cheese manufacture either singly or more commonly in a blend of several types of ES.

Numerous factors, including $\mathrm{pH}$, affect the melting and textural characteristics of process cheese (Mulsow et al., 2007). Many of these factors, which are not well understood at the molecular level, are interrelated and have a combined effect on meltability and texture. It has 
been reported that the use of SHMP produces hard and poorly meltable process cheese (Thomas, 1973; Gupta et al., 1984; Carić et al., 1985). However, it appears that no studies exist on the effect of SHMP on process cheese properties where $\mathrm{pH}$ was kept constant (to avoid $\mathrm{pH}$ as a confounding factor). Gupta et al. (1984) reported that the use of SHMP resulted in process cheese with low $\mathrm{pH}$ values, which could have contributed to the poor textural attributes. Lu et al. (2008) reported that increasing the $\mathrm{pH}$ resulted in improved meltability for process cheese made with SHMP. Cooking time also affects the properties of process cheese (Rayan et al., 1980; Shirashoji et al., 2006). One method by which cooking time affects process cheese is by increasing the extent of shearing of curd and thus improving the emulsification of fat (i.e., by reducing the size of emulsified fat globules; Shimp, 1985; Kapoor and Metzger, 2008).

The objective of this study was to investigate the effects of various concentrations of SHMP and cooking times on the rheological and textural properties of process cheese. Because $\mathrm{pH}$ is well known to influence the texture of process cheese made with SHMP (Lu et al., 2008), all samples were adjusted to a constant $\mathrm{pH}$ value $(\sim 5.6)$.

\section{MATERIALS AND METHODS}

\section{Materials}

We used 4-mo-old Cheddar cheese that was always obtained from the same cheese factory (Alto Dairy Cooperative, Waupun, WI). This cheese was selected because it was made using a consistent cheese making procedure and the cheeses always had similar composition (moisture, 37\%; fat, 34\%; protein, 26\%; $669 \mathrm{mg}$ of $\mathrm{Ca} / 100 \mathrm{~g}$ of cheese; mean of $\mathrm{n}=3$ ). A single cheese was used instead of a blend of cheeses to simplify the experimental system. The ES used was SHMP (Hexametaphos, ICL Performance Products LP, St. Louis, MO). For SHMP, an average P chain length of 5.6 was determined by the method described by Odagiri and Nickerson (1964). The $\mathrm{pH}$ modifiers used were 50\% sodium hydroxide (Fisher Scientific, Pittsburgh, PA) or $88 \%$ lactic acid (Brenntag Great Lakes LLC, Wauwatosa, WI).

\section{Process Cheese Manufacture}

Process cheeses were prepared with a Blentech twinscrew cooker (Blentech Corp., Rohnert Park, CA) as described by Shirashoji et al. (2006). During mixing, $50 \%$ sodium hydroxide or $88 \%$ lactic acid were added to adjust the $\mathrm{pH}$ of the final product to approximately 5.6. Preliminary small batches of process cheese were prepared with each ES level to determine the amount of acid or base that would be required in cheese manufacture. After cooking, process cheese blocks were packed, vacuum sealed, and stored at $5^{\circ} \mathrm{C}$. The textural, rheological, and compositional analyses were determined 7 d after manufacture.

\section{Rheological Measurements}

Rheological properties of pasteurized process cheese were measured by dynamic small amplitude oscillatory rheology as described previously (Shirashoji et al., 2006). Cheeses were heated from 5 to $85^{\circ} \mathrm{C}$ at a heating rate of $1^{\circ} \mathrm{C} / \mathrm{min}$. A frequency of $0.08 \mathrm{~Hz}$ and a strain of $0.5 \%$ were applied to measure the storage modulus $\left(\mathbf{G}^{\prime}\right)$ and loss tangent $(\mathbf{L T})$. Rheological measurements of hot process cheese were measured as described by Shirashoji et al. (2006). Process cheese that had been cooked at $80^{\circ} \mathrm{C}$ for $10 \mathrm{~min}$ was rapidly transferred to the rheometer (tests were started within $4 \mathrm{~min}$ ) and held at $80^{\circ} \mathrm{C}$ for $30 \mathrm{~min}$.

\section{Acid-Base Titration}

Acid-base titrations were performed as described by Hassan et al. (2004). Process cheese homogenates were prepared for titration by dispersing $8.0 \mathrm{~g}$ of grated process cheese in $40 \mathrm{~mL}$ of distilled water. This dispersion was titrated from its initial $\mathrm{pH}$ to $\mathrm{pH} 3.0$ with $0.5 \mathrm{~N}$ hydrochloric acid and then from $\mathrm{pH} 3.0$ to 8.0 with 0.5 $N$ sodium hydroxide. Buffering indices were calculated for each addition of titrant and buffering curves were prepared by plotting these indices as a function of $\mathrm{pH}$ (Hassan et al., 2004). Triplicate titrations were typically performed and additional replicates were done if the triplicate curves did not closely overlap.

\section{Texture Profile Analysis, Uniaxial Compression, and Meltability}

Texture profile analysis (TPA) and uniaxial compression were measured using a TA.XT2 Texture Analyzer (Texture Technologies Corp., Scarsdale, NY) equipped with a $25-\mathrm{kg}$ load cell. Samples (16 mm diameter, 17.5 $\mathrm{mm}$ height) were cut from process cheese blocks using a cork borer. For TPA test, cheese was compressed to $80 \%$ of the original height by a $50-\mathrm{mm}$ aluminum cylinder test probe with a cross-head speed of $0.8 \mathrm{~mm} / \mathrm{s}$. For uniaxial compression, cheese was compressed to $20 \%$ of original height using the same test probe and cross-head speed as for the TPA test. All tests were performed at $5^{\circ} \mathrm{C}$ and tests were replicated at least 5 times. Meltability was measured by the modified Schreiber test (Muthukumarappan et al., 1999a) and 
Table 1. Values of independent variables of each experiment in coded and actual values for the central composite experimental design ${ }^{1}$

\begin{tabular}{|c|c|c|c|c|}
\hline \multirow[b]{2}{*}{ Treatment no. } & \multicolumn{2}{|c|}{ Coded value } & \multicolumn{2}{|c|}{ Actual value } \\
\hline & Concentration of ES & Holding time & Concentration of ES (\%) & Holding time (min) \\
\hline 1 & 0 & 0 & 1.50 & 10.0 \\
\hline 2 & -1 & -1 & 0.62 & 2.90 \\
\hline 3 & 0 & 0 & 1.50 & 10.0 \\
\hline 4 & +1 & +1 & 2.38 & 17.1 \\
\hline 5 & +1 & -1 & 2.38 & 2.90 \\
\hline 6 & 0 & $+\alpha^{2}$ & 1.50 & 20.0 \\
\hline 7 & 0 & $-\alpha$ & 1.50 & 0.0 \\
\hline 8 & $-\alpha$ & 0 & 0.25 & 10.0 \\
\hline 9 & 0 & 0 & 1.50 & 10.0 \\
\hline 10 & $+\alpha$ & 0 & 2.75 & 10.0 \\
\hline 11 & -1 & +1 & 0.62 & 17.1 \\
\hline 12 & 0 & 0 & 1.50 & 10.0 \\
\hline
\end{tabular}

the degree of flow (DOF) was obtained from the UWMeltprofiler (Muthukumarappan et al., 1999b). The modified Schreiber and DOF procedures described by Shirashoji et al. (2006) were followed. These tests were replicated 4 times.

\section{Composition Analysis}

Cheeses were analyzed for moisture (IDF, 1982), fat (Marshall, 1992), protein (IDF, 1986), and $\mathrm{pH}$ by insertion of a $\mathrm{pH}$ probe $(\mathrm{pH}$ meter $420 \mathrm{~A}$, Orion Research, Beverley, MA) into the cheese. The total Ca and $\mathrm{P}$, insoluble $\mathrm{Ca}$, and insoluble $\mathrm{P}$ contents of process cheese were measured as described by Shirashoji et al. (2006).

\section{Experimental Design and Statistical Analysis}

The effects of concentration of ES and holding time on the rheological, physical, and chemical characteristics of process Cheddar cheese were investigated using a central composite rotatable design (Mullen and Ennis, 1979) and response surface methodology (Montgomery, 2001; Shirashoji et al., 2006). A 2-level factorial experimental design was chosen to study the effects of the independent variables (ES concentration and holding time) with 2 star points $(\alpha=1.414)$ and 4 replicates of the center point (Table 1 ). The coded variables were related to the real units by Equations 1 and 2:

$$
\begin{aligned}
\text { Coded concentration of ES } & =\frac{\text { concentration of ES }(\%)-1.5}{0.884}, \\
\text { Coded holding time } & =\frac{\text { holding time }(\min )-10}{7.071} .
\end{aligned}
$$

Results were analyzed by multiple (step-wise) regression and response surface methodology using the Statgraphics program (version 5.1 plus, Manugistics, Rockville, MD). Dependent variables were estimated using second-order (polynomial) models to provide a good description of the geometric slope of response surfaces. Step-wise regression was used to eliminate insignificant factors $(F$-value $<4)$ using backward selection, which begins with all the variables in a model and removes them one at a time to simplify the model (Montgomery, 2001).

\section{RESULTS}

\section{Composition}

The $\mathrm{pH}$ values for the various cheese samples were similar (with a narrow range: $\mathrm{pH}$ 5.50-5.63; Table 2) and the moisture contents were also similar (range: 37.3-38.0; Table 2). This small variation in cheese composition should not have a major effect on the texture or rheological results.

\section{Rheological Properties}

The effects of ES concentration on the rheological properties of process cheese made with SHMP during heating are shown in Figures 1a and b. The rheological properties of the natural Cheddar cheese are also shown for comparison purposes. The $\mathrm{G}^{\prime}$ value of all cheeses decreased with temperature from 5 to $70^{\circ} \mathrm{C}$. The $\mathrm{G}^{\prime}$ value of the process cheese made with 1.50 and $2.75 \% \mathrm{ES}$, as well as natural cheese, increased again at $>70^{\circ} \mathrm{C}$, although cheese made with $0.25 \%$ ES continued to decrease with increasing temperature throughout the entire heating range. This increase in $\mathrm{G}^{\prime}$ at high 

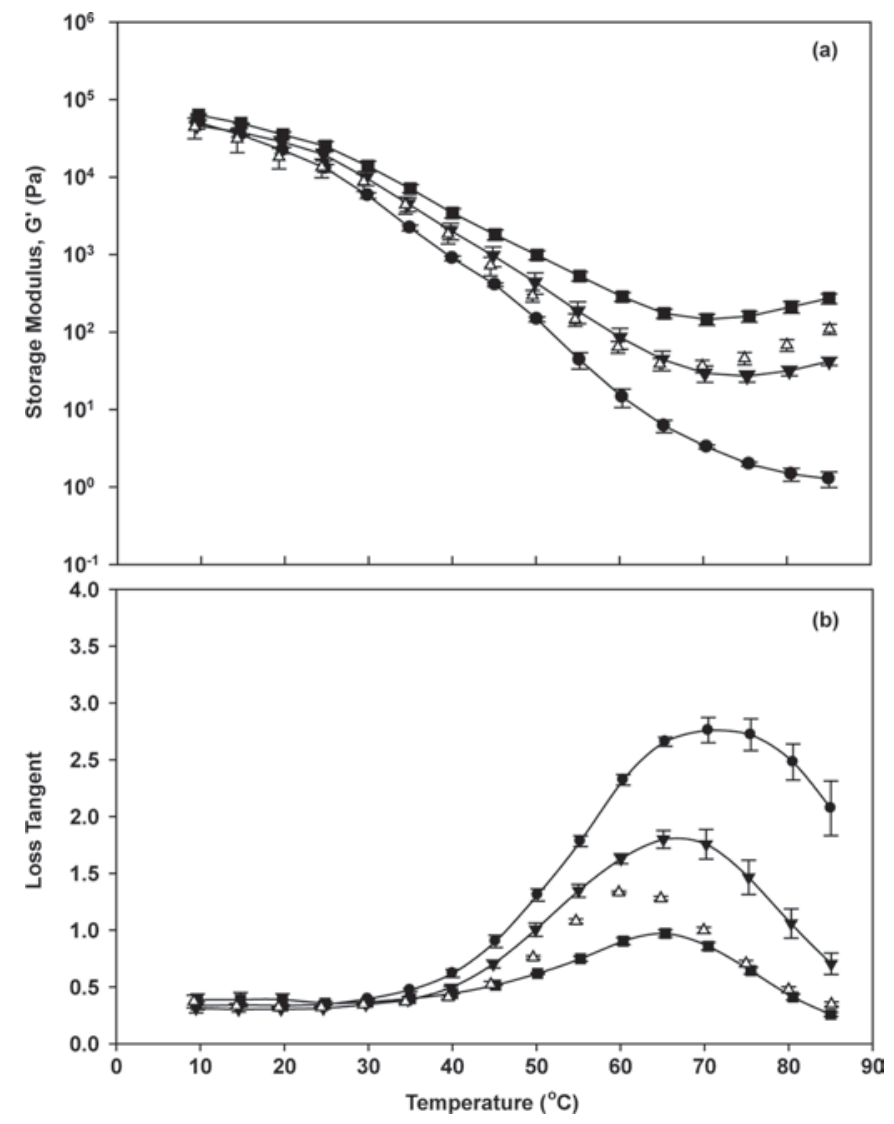

Figure 1. a) Storage modulus and b) loss tangent as a function of temperature for process cheeses made with various concentrations of sodium hexametaphosphate and the natural Cheddar cheese used in process cheese making $(\Delta)$. Sodium hexametaphosphate concentrations: $0.25 \%(\bullet), 1.50 \%(\mathbf{v})$, and $2.75 \%(\mathbf{\square})$. Holding time was $10 \mathrm{~min}$ for all process cheese samples. The data represent means $(\mathrm{n}=3)$, and the error bars represent the standard deviation.

temperature was not observed with any of the process cheeses made with trisodium citrate (TSC) in our previous study (Shirashoji et al., 2006). The LT value of process cheese measured at $>50^{\circ} \mathrm{C}$ decreased with an increase in ES concentration. Process cheese made with $2.75 \%$ SHMP had LT values that were $<1$ over the entire heating range. Samples with LT values $<1$ do not exhibit flow (Lucey et al., 2003).

The response surface plots for $\mathrm{G}^{\prime}$ values at $70^{\circ} \mathrm{C}$ and $\mathrm{LT}$ values at $50^{\circ} \mathrm{C}$ are shown in Figures $2 \mathrm{a}$ and b, respectively. The $\mathrm{G}^{\prime}$ values at $70^{\circ} \mathrm{C}$ increased with an increase in ES concentration; this was especially obvious for long holding times (Figure 2a). The LT value at $50^{\circ} \mathrm{C}$ decreased with increasing ES concentration and with longer holding times (Figure $2 \mathrm{~b}$ ).

\section{Textural Properties}

The response surface plot for hardness values obtained from TPA is shown in Figure 2c. There was an increase
Table 2. Composition of process cheese made with sodium hexametaphosphate for each experimental treatment

\begin{tabular}{llcc}
\hline Treatment no. & $\mathrm{pH}$ & Moisture $(\%)$ & Fat (\%) \\
\hline 1 & 5.52 & 37.61 & 32.40 \\
2 & 5.56 & 37.96 & 32.81 \\
3 & 5.53 & 37.76 & 32.18 \\
4 & 5.50 & 37.85 & 31.71 \\
5 & 5.51 & 37.38 & 32.72 \\
6 & 5.53 & 37.67 & 32.63 \\
7 & 5.62 & 37.94 & 32.09 \\
8 & 5.55 & 37.50 & 32.66 \\
9 & 5.60 & 37.66 & 32.45 \\
10 & 5.53 & 37.60 & 31.25 \\
11 & 5.63 & 37.31 & 32.21 \\
12 & 5.58 & 37.60 & 31.68 \\
\hline
\end{tabular}

in hardness of cheese as ES concentration increased. Hardness values greatly increased at longer holding time and high ES concentration, which was similar to the trends observed in process cheese made with TSC (Shirashoji et al., 2006). Uniaxial compression profiles showed that process cheese made with the highest ES concentration $(2.75 \%)$ exhibited pronounced fracture at approximately $45 \%$ strain (Figure 3 ). This was a similar profile to the natural Cheddar cheese used as raw material, which indicated that at high ES concentration process cheese became brittle. Process cheese made with the lowest ES concentration did not exhibit any fracture. Gupta et al. (1984) also reported that process cheese made with SHMP exhibited fracture, although in that study the process cheeses had low $\mathrm{pH}$ values $(<5.2)$, which could have promoted brittleness.

\section{Meltability}

Changes in cheese height during melting, obtained by the UW-Meltprofiler, for process cheese made with various ES concentrations are shown in Figure 4. The profile for the natural cheese used for process cheese making is also shown for comparison purpose (Figure 4). Cheese made with $0.25 \%$ SHMP melted and flowed at a lower temperature than the other process cheese samples. Process cheese with $2.75 \%$ SHMP had very limited flow. The response surface plot for the DOF is shown in Figure 2d. The DOF decreased as the ES concentration increased. At the lowest ES concentration $(0.25 \%)$ the DOF increased with increasing holding time, whereas with higher ES concentration there was a decrease in the DOF with an increase in the holding time (Figure 2d).

\section{Insoluble Ca and $P$}

The response surface plot for the insoluble Ca content as a function of total $\mathrm{Ca}$ in cheese is shown in Figure 

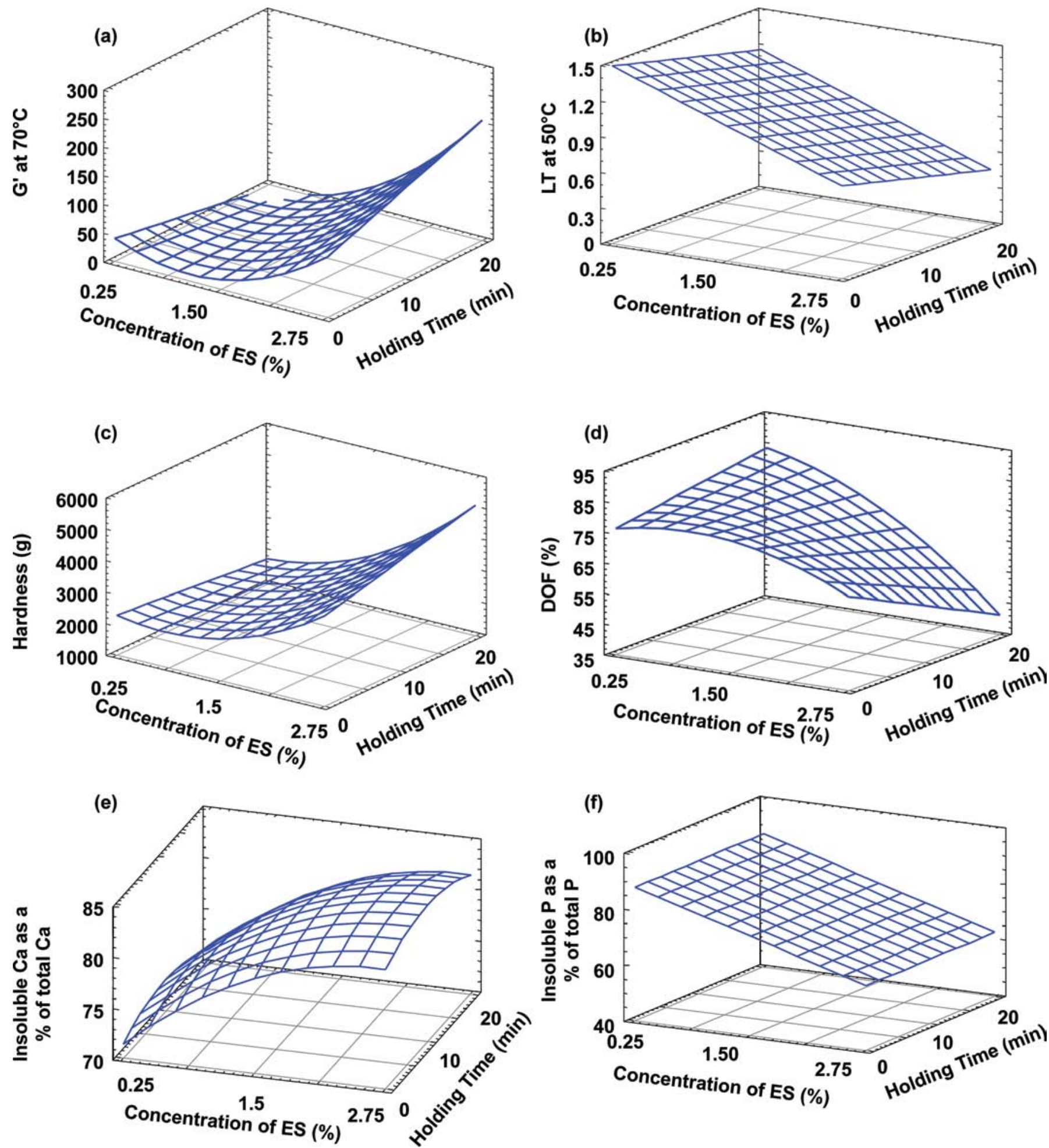

Figure 2. Response surface plots for the effect of concentrations of emulsifying salt (ES) and holding times on a) storage modulus (G') at $70^{\circ} \mathrm{C}$, b) loss tangent (LT) at $50^{\circ} \mathrm{C}$, c) hardness, d) degree of flow (DOF) at $60^{\circ} \mathrm{C}$ from the UW-Meltprofiler (Muthukumarappan et al., $1999 \mathrm{~b}$ ), e) insoluble $\mathrm{Ca}$ as a percentage of total $\mathrm{Ca}$, and $\mathrm{f}$ ) insoluble $\mathrm{P}$ as a percentage of total $\mathrm{P}$ in process cheese. Color version available in the online PDF. 


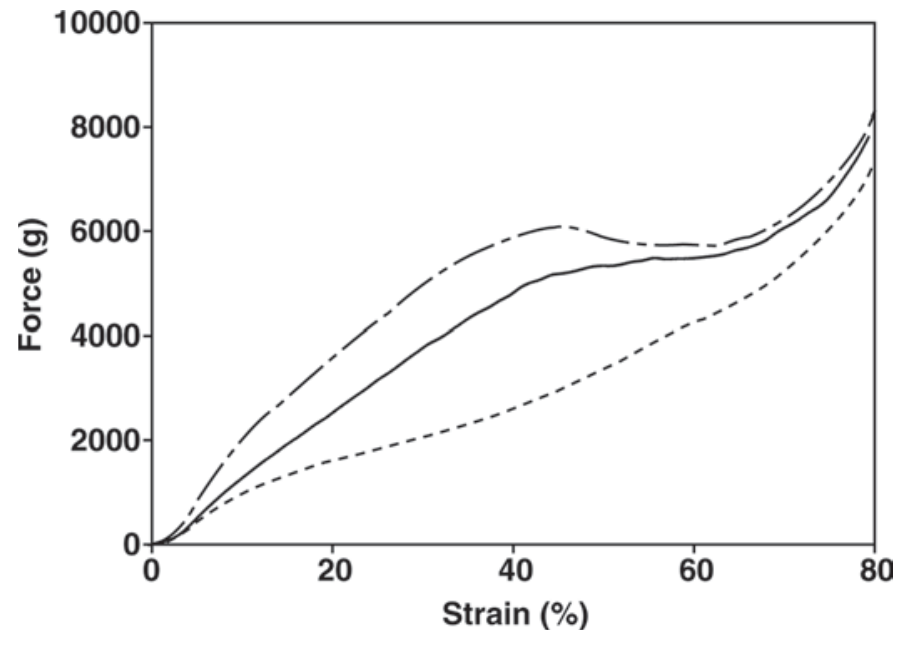

Figure 3. Stress-strain curves during uniaxial compression of process cheeses to $20 \%$ of the original height. Cheeses made with various concentrations of sodium hexametaphosphate: 0.25 (dotted line), 1.50 (solid line), and $2.75 \%$ (dashed-dotted line). Holding time was $10 \mathrm{~min}$ for all process cheese samples. The data represent means $(n \geq 5)$, and the error bars represent the standard deviation.

2e. The insoluble Ca content of process cheese increased with an increase in ES concentration. The holding time did not have a significant effect on the insoluble $\mathrm{Ca}$ content. The response surface plot for the amount of insoluble $\mathrm{P}$ as a percentage of total $\mathrm{P}$ in cheese is shown in Figure 2f. The proportion of insoluble $\mathrm{P}$ as a percentage of total $\mathrm{P}$ decreased with increasing ES levels. This indicates that a proportion of the added $\mathrm{P}$ remained in the serum phase as a soluble salt. The total amount of insoluble $\mathrm{P}$ in cheese increased as ES concentration increased (Table 3); the added SHMP contained P, thus increasing the ES level increased the P content. Holding time did not significantly influence the insoluble $\mathrm{P}$ content (Table 3).

\section{Acid-Base Buffering Curves}

The acid-base buffering curves of natural cheese and process cheese made with various concentrations of SHMP are shown in Figure 5. There was no significant difference in buffering curves of cheese with different holding times (results not shown). There was an increase in the buffering peak observed during acidification, with an increase in the ES concentration. The buffering peak observed during acidification was shifted to lower $\mathrm{pH}$ values with increasing ES concentration. In natural Cheddar cheese, the buffering peak at approximately $\mathrm{pH} 4.8$ is attributable to the release of phosphate ions with the solubilization of residual insoluble Ca phosphate (CCP; Lucey and Fox, 1993). Mizuno and Lucey (2005) observed a similar trend in acid-base buffering curves of milk protein solution containing SHMP; they suggested that the shift of buffering peak may be attributable to the formation of a new type of Ca phosphate. A buffering peak was observed at approximately $\mathrm{pH} 6$ during the back titration of acidified (natural) Cheddar

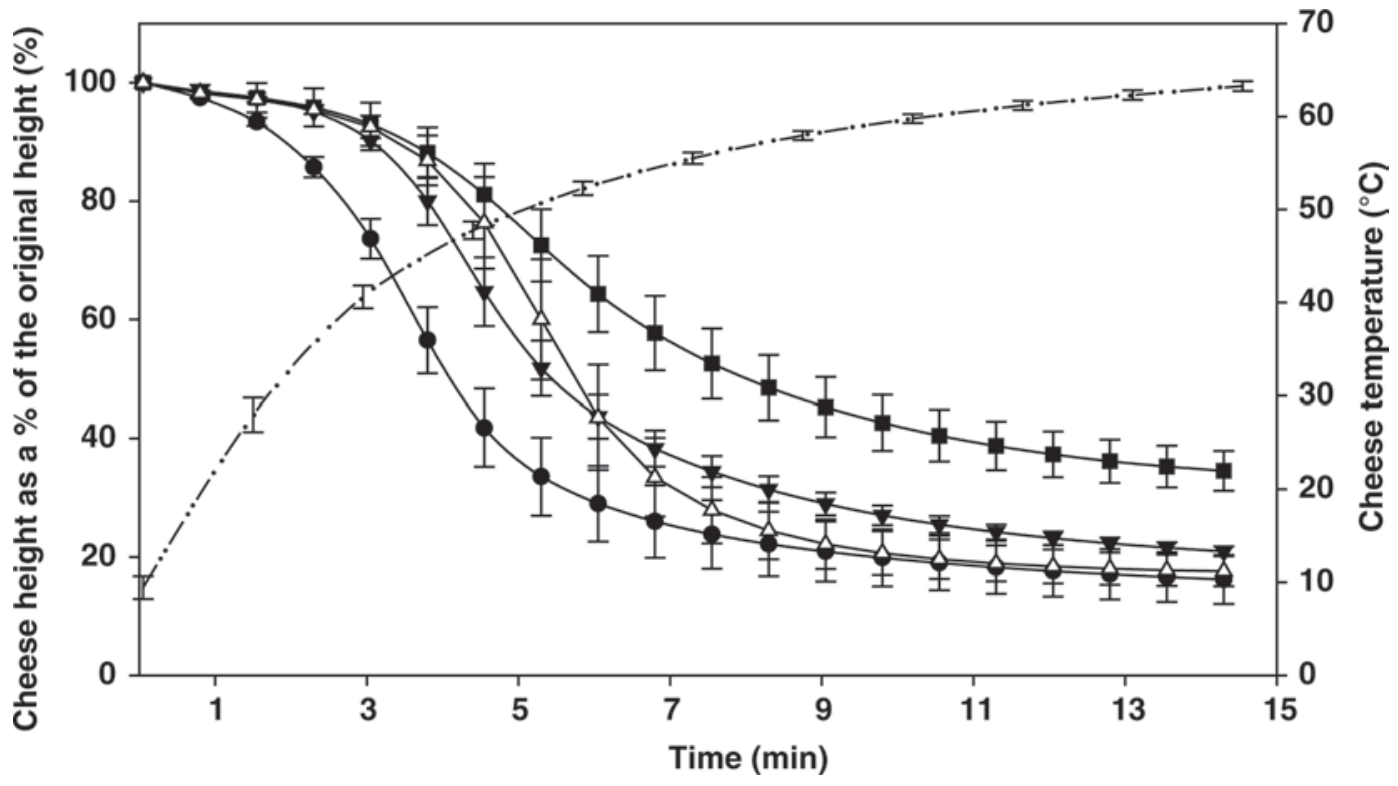

Figure 4. Changes in cheese height as a percentage of the original height from the UW-Meltprofiler (Muthukumarappan et al., 1999b) for process cheese made with various concentrations of sodium hexametaphosphate and natural Cheddar cheese used as a base ingredient $(\Delta)$. Sodium hexametaphosphate concentrations: $0.25 \%(\boldsymbol{\bullet}), 1.50 \%(\boldsymbol{\nabla})$, and $2.75 \%(\boldsymbol{\nabla})$. Cheese temperature is indicated by a dashed line. The data represent means $(\mathrm{n}=3)$, and the error bars represent the standard deviation. 
Table 3. Second-order polynomial models describing dependent variables

\begin{tabular}{|c|c|c|c|c|}
\hline Dependent variable & Independent variable ${ }^{1}$ & Coefficient & $\mathrm{R}^{2}(\text { adjusted })^{2}$ & $P$-value \\
\hline \multirow{2}{*}{ Loss tangent at $50^{\circ} \mathrm{C}$} & $\mathrm{ESC}^{* * *}$ & -0.253903 & \multirow{2}{*}{0.86} & \multirow{2}{*}{$<0.001$} \\
\hline & Holding time** & -0.11488 & & \\
\hline \multirow{3}{*}{ Degree of flow at $60^{\circ} \mathrm{C}$ from UW-Meltprofiler ${ }^{3}$} & $\mathrm{ESC}^{* * *}$ & -9.445 & \multirow{3}{*}{0.87} & \multirow{3}{*}{$<0.001$} \\
\hline & Holding time* & -2.901 & & \\
\hline & ESC $\times$ holding time* & -4.114 & & \\
\hline \multirow{4}{*}{ TPA hardness ${ }^{4}$} & $\mathrm{ESC}^{* * *}$ & 881.6 & \multirow{4}{*}{0.96} & \multirow{4}{*}{$<0.001$} \\
\hline & Holding time* & 134.0 & & \\
\hline & ESC $\times$ holding time* & 220.8 & & \\
\hline & $\mathrm{ESC}^{2 * * *}$ & 380.1 & & \\
\hline \multirow[t]{3}{*}{ TPA chewiness } & Constant & 1,645 & \multirow[t]{3}{*}{0.88} & \multirow[t]{3}{*}{$<0.001$} \\
\hline & $\mathrm{ESC}^{* * *}$ & 601.7 & & \\
\hline & $\mathrm{ESC}^{2} \dagger$ & 150.5 & & \\
\hline \multirow[t]{3}{*}{ Insoluble P content (mg/100 g of cheese) } & Constant & 624.5 & \multirow[t]{3}{*}{0.87} & \multirow[t]{3}{*}{$<0.001$} \\
\hline & $\mathrm{ESC}^{* * *}$ & 91.80 & & \\
\hline & $\mathrm{ESC}^{2 *}$ & -30.27 & & \\
\hline \multirow[t]{2}{*}{ Insoluble $\mathrm{P}$ (\% of total Ca) } & Constant & 75.48 & \multirow[t]{2}{*}{0.98} & \multirow[t]{2}{*}{$<0.001$} \\
\hline & $\mathrm{ESC}^{* * *}$ & -8.80 & & \\
\hline \multirow[t]{4}{*}{ Insoluble $\mathrm{Ca}(\%$ of total $\mathrm{Ca}$ ) } & Constant & 80.99 & \multirow[t]{4}{*}{0.92} & \multirow[t]{4}{*}{$<0.001$} \\
\hline & $\mathrm{ESC}^{* *}$ & 3.68458 & & \\
\hline & $\mathrm{ESC}^{2 *}$ & -1.42009 & & \\
\hline & Holding time $^{2 *}$ & -0.86507 & & \\
\hline \multirow{5}{*}{ Schreiber melt area ${ }^{5}$} & Constant & 21.8705 & \multirow[t]{5}{*}{0.92} & \multirow[t]{5}{*}{$<0.001$} \\
\hline & $\mathrm{ESC}^{* * *}$ & -5.50014 & & \\
\hline & Holding time* & -1.66998 & & \\
\hline & ESC $\times$ holding time* & -2.2525 & & \\
\hline & $\mathrm{ESC}^{2 * * *}$ & 1.69681 & & \\
\hline
\end{tabular}

${ }^{1} \mathrm{ESC}=$ emulsifying salt concentration.

${ }^{2} \mathrm{R}^{2}$ values were adjusted for the degree of freedom.

${ }^{3}$ Muthukumarappan et al. (1999b).

${ }^{4} \mathrm{TPA}=$ texture profile analysis.

${ }^{5}$ Muthukumarappan et al. (1999a).

$\dagger P<0.1{ }^{*} P<0.05 ;{ }^{*} P<0.01 ; * * * P<0.001$.

cheese, in agreement with previous studies (Lucey and Fox, 1993; Hassan et al., 2004). With an increase in the concentration of SHMP, this buffering peak during back titration of process cheese disappeared.

\section{Rheology of Hot Process Cheese}

The rheological properties of hot process cheese are shown in Figure 6. At low ES levels, the $G^{\prime}$ values changed little during holding at $80^{\circ} \mathrm{C}$ (Figure 6a). At high ES levels, a steady increase in $\mathrm{G}^{\prime}$ values was observed during holding. The use of low concentrations of ES also resulted in low values of the LT when the hot process cheese was tested after 4 min of cooking (Figure $6 \mathrm{~b})$. Low LT values of hot process cheese could indicate poorly dispersed CN (Shirashoji et al., 2006). A slight decrease in LT values during holding was observed for the cheese made with the low ES level. Very high initial LT values were observed for cheeses made with high ES levels, although the LT values steadily decreased during holding of the hot cheese.

\section{DISCUSSION}

We believe that the texture of process cheese can be explained using the model for cheese texture proposed by Lucey et al. (2003). Heating, shearing, and the action of ES result in the disruption of attractive interactions in the system and dispersion of the insoluble $\mathrm{CN}$ matrix. During cooling there is reassociation of $\mathrm{CN}$ molecules as well as formation of ES-Ca complexes that can help crosslink $\mathrm{CN}$ in the gelling system. The different types of ES differ in their Ca binding and their abilities to disperse or crosslink CN. The ES concentra- 


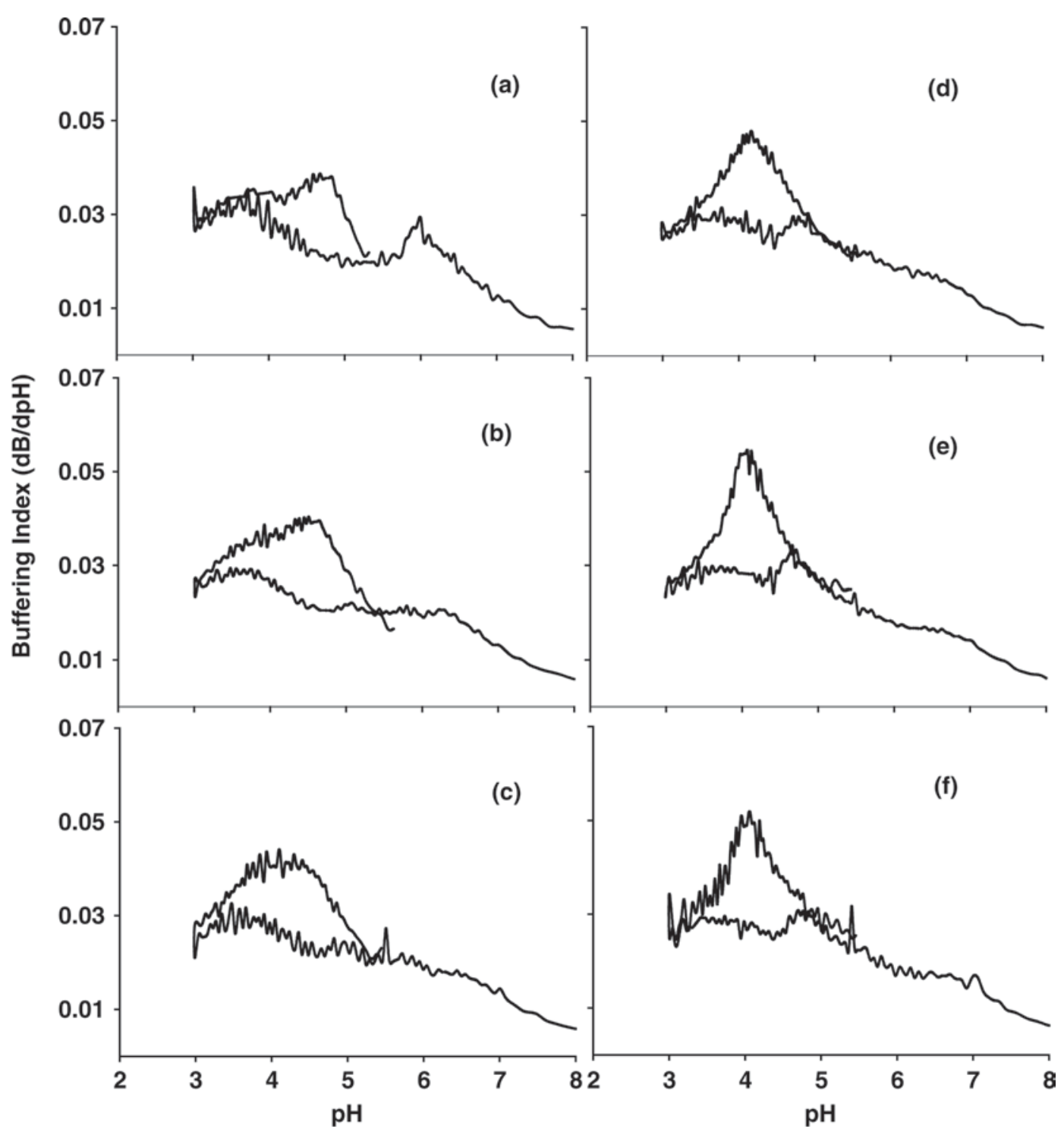

Figure 5. Acid-base buffering curves for a) natural Cheddar cheese as the cheese making ingredient and process cheeses made with various sodium hexametaphosphate concentrations: b) $0.25 \%$, c) $0.62 \%$, d) $1.50 \%$, e) $2.38 \%$, and f) $2.75 \%$.

tion and holding time influence both the disruption of the attractive interaction in cheese curd and the number and type of attractive interactions formed during the cooling-gelation phase.

Several factors could explain the effect of increasing SHMP concentration on cheese texture. Increasing the concentration of SHMP used in process cheese resulted in an increase in hardness (Figure 2c) and the $\mathrm{G}^{\prime}$ value at $70^{\circ} \mathrm{C}$ (Figure $2 \mathrm{a}$ ) and a decrease in the $\mathrm{LT}$ value at $50^{\circ} \mathrm{C}$ (Figure 2b) and DOF (Figure 2d). These effects were not attributable to any compositional factors because we manufactured the cheeses to a constant composition. We believe that the higher hardness and lower meltability with increasing SHMP concentration is attributable to a combination of enhanced CN dispersion, Ca chelation, and ion exchange. One of the key functions of ES, such as SHMP, is the ability to disperse (sometimes called peptization) the insoluble CN matrix in natural cheese. Polyphosphates have a greater $\mathrm{CN}$ dispersing ability compared with orthophosphates or TSC (Lee et al., 1986; Molins, 1991; Dimitreli et al., 2005; Mizuno and Lucey, 2005). The addition of SHMP to milk rapidly causes $\mathrm{CN}$ dispersion (Vujicic et al., 1968). The use of SHMP in process cheese greatly increases CN dispersion (hydration, peptization, or swelling) compared with TSC or orthophosphates (Lee et al., 1986; Guinee et al., 2004), although in these studies the $\mathrm{pH}$ of cheese was not kept constant. Increasing the 
concentration of polyphosphate used in process cheese resulted in an increase in soluble nitrogen content (indicating greater CN dispersion; Lee and Alais, 1980). Hot process cheese after holding at $80^{\circ} \mathrm{C}$ for $10 \mathrm{~min}$ exhibited very large LT values compared with process cheeses made with low ES concentration (Figure 6b). The high LT values in hot process cheese made with high ES concentrations suggest that increasing the concentration of SHMP greatly increased CN dispersion.

The ability of SHMP to disperse $\mathrm{CN}$ is $\mathrm{pH}$-dependent with low ability near pH 5 (Dimitreli et al., 2005). Our cheeses were all at $\mathrm{pH} 5.6$, and at this $\mathrm{pH}$ value SHMP should still be effective at causing $\mathrm{CN}$ dispersion. These highly dispersed $\mathrm{CN}$ molecules then reassociate during cooling to form a fine-structured gel network (some CN reassociation may be occurring in the hot product as evidenced by the increase in $\mathrm{G}^{\prime}$ values during the holding of cheese at $80^{\circ} \mathrm{C}$; Figure 6 ). The greater the degree of $\mathrm{CN}$ dispersion, the firmer, more cross-linked, and less meltable is the final process cheese. This agrees with the similar trend reported for process cheese made with increasing concentrations of TSC (Shirashoji et al., 2006). Johnston and Murphy (1992) reported that there was greater $\mathrm{CN}$ dispersion in milk with an increase in SHMP levels; acid gels made from these SHMP-treated milks had improved gel textural properties.

Polyphosphates also have a strong ability to complex $\mathrm{Ca}$, and we can rank phosphates and citrates in the following order: long-chain phosphates $>$ tripolyphosphate $>$ pyrophosphate $>$ citrate $>$ orthophosphate (Van Wazer and Callis, 1958). The strong Ca binding properties of SHMP should result in greater dispersion of $\mathrm{CN}$ because of the loss of CCP cross-links present in natural cheese.

The highly charged anionic nature of polyphosphates causes them to be attracted to the oppositely charged groups on other long-chain polyelectrolytes, such as proteins (Van Wazer and Callis, 1958). In our process cheeses, association of polyphosphate with $\mathrm{CN}$ should increase the charge repulsion between $\mathrm{CN}$ molecules. In some circumstances the addition of phosphates to milk can cause gelation (Mizuno and Lucey, 2007). Sodium hexametaphosphate was less effective at gelling CN than tetrasodium pyrophosphate. One factor that inhibits gelation of $\mathrm{CN}$ is that polyphosphates introduce more charge repulsion to $\mathrm{CN}$ because of their multiple negative charges (i.e., polyelectrolyte nature) compared with tetrasodium pyrophosphate.

Another possible factor that could contribute to the increased hardness and reduced meltability of cheese made with high concentration of SHMP is the formation of new Ca phosphate linkages within the cheese network (Gupta et al., 1984). Taneya et al. (1980) reported that long protein strands were observed in a process cheese

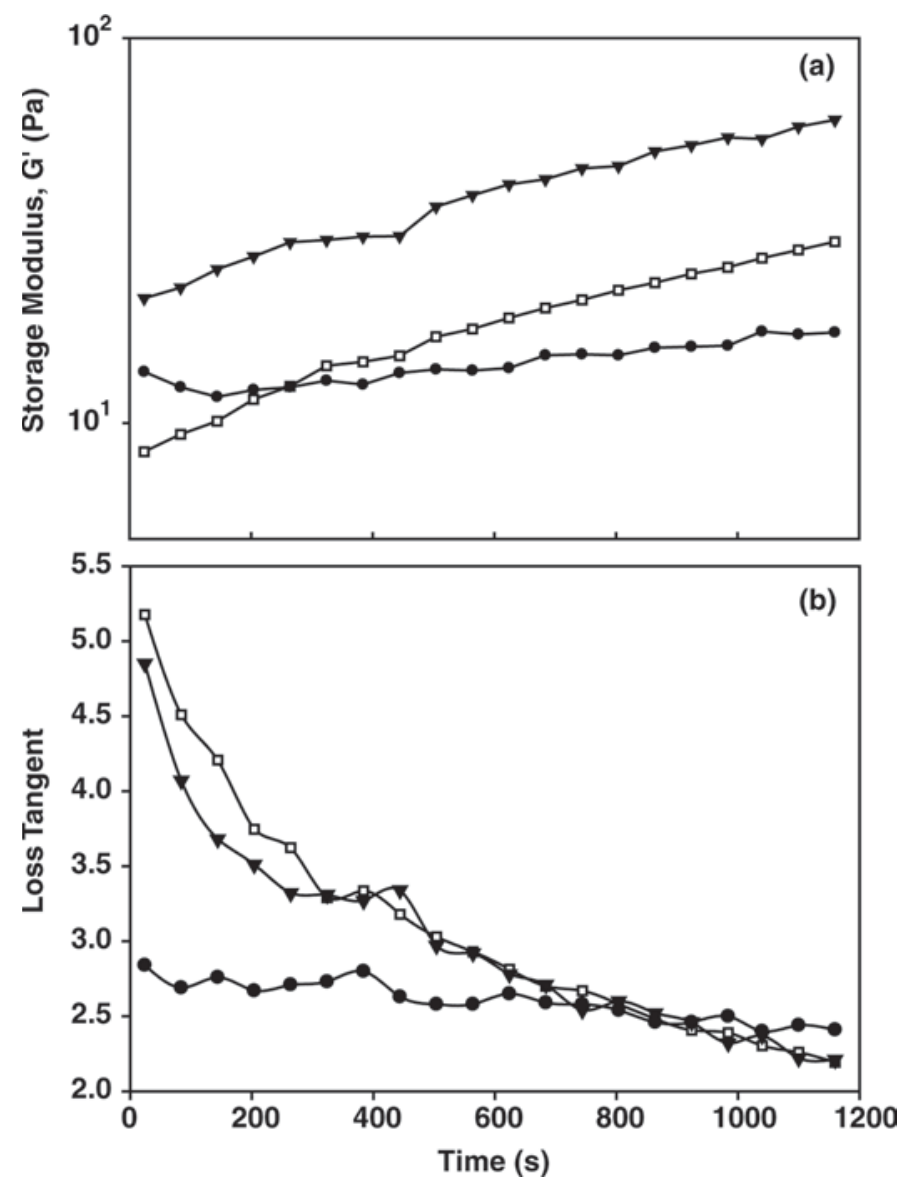

Figure 6. a) Storage modulus and b) loss tangent for melted process cheeses made with various concentrations of sodium hexametaphosphate $[0.25 \%(\bullet), 1.50 \%(\square)$, and $2.75 \%(\mathbf{v})]$ during holding at $80^{\circ} \mathrm{C}$. The data for $1.50 \%$ sodium hexametaphosphate level represent means $(\mathrm{n}=4)$. Other curves are single tests. Rheological measurements were started $4 \mathrm{~min}$ after process cheese was taken out of a cooker where it was heated at $80^{\circ} \mathrm{C}$ for $10 \mathrm{~min}$.

made with sodium polyphosphate, whereas these long strands were not observed in a process cheese made with TSC. Long CN strands in process cheese could have resulted from the formation of new Ca phosphate linkages between $\mathrm{CN}$. The insoluble Ca (Figure 2e) and insoluble $\mathrm{P}$ content (Table 3 ) of process cheese increased with increasing SHMP concentration. The addition of SHMP to milk protein concentrate at $\mathrm{pH}$ 5.8 increased CN-bound Ca (Mizuno and Lucey, 2005). Polyphosphates bind $\mathrm{Ca}$ from the native $\mathrm{CCP}$ (which help to disperse the $\mathrm{CN}$ micelles), but these new $\mathrm{Ca}$ phosphates complexes can associate with the dispersed CN (Odagiri and Nickerson, 1965; Mizuno and Lucey, 2005). Lee and Alais (1980) reported that the use of polyphosphates resulted in a high level of insoluble $\mathrm{P}$ in process cheese. Johnston and Murphy (1992) reported that skim milk solutions with polyphosphate contained a high proportion of nonsedimentable (soluble) CN. 
Apart from the lowest ES concentration, all other process cheese samples exhibited an increase in $\mathrm{G}^{\prime}$ at temperatures $>70^{\circ} \mathrm{C}$ during heating (Figure 1a). Udayarajan et al. (2005) suggested that the increase in $\mathrm{G}^{\prime}$ value of natural Cheddar cheese at high temperature was attributable to the heat-induced formation of additional Ca phosphate cross-links between CN.

The acid-base buffering profiles of process cheese indicate that the addition of SHMP caused a shift in the $\mathrm{pH}$ value where the buffering peak occurred during acidification (Figure 5). Lucey et al. (1993) suggested that a change in location or shape of the buffering peak observed during the acidification of milk might be attributable to some shift in the structure, or composition, or both, of the indigenous CCP. The buffering profiles of process cheese suggest that increasing the SHMP content altered the type and concentration of Ca phosphate salts present in the cheese network.

A small quantity of SHMP (0.25\%) was not enough to efficiently disperse the CN network even with the use of long holding times during the cooking step. Consequently, fat was poorly emulsified (results not shown) and the process cheese was relatively soft (Figure 2c) and had good meltability (Figure 2d).

Holding time resulted in a significant decrease in the $\mathrm{LT}$ value at $50^{\circ} \mathrm{C}, \mathrm{DOF}$, and Schreiber melt area and a significant increase in hardness and the $G^{\prime}$ value at $70^{\circ} \mathrm{C}$ (Table 3). Long holding times have previously been reported to reduce melt and increase hardness of process cheese (Rayan et al., 1980). An increase in the hold time also increases the extent of shear applied to the process cheese; this creates smaller homogenized fat globules that reinforce the matrix formed during cooling. During prolonged holding time at high temperatures, it is likely that some heat-induced CN aggregation occurred. Although increasing the concentration of ES used in process cheese resulted in an increase in the initial measured LT of the hot product (i.e., measured after a holding time of $10 \mathrm{~min}$ at $80^{\circ} \mathrm{C}$ ), during (further) prolonged holding there was a substantial decrease in the LT and an increase in $\mathrm{G}^{\prime}$ values (Figure 6). Panouillé et al. (2003) observed that heat-induced aggregation and gelation of CN micelles could occur in the presence of sodium polyphosphates. Holding time had no significant effect on the insoluble $\mathrm{Ca}$ or $\mathrm{P}$ content (Table 3). Because SHMP is a very effective Ca chelating agent, the time required to heat the process cheese to $80^{\circ} \mathrm{C}$ was likely sufficient to allow SHMP to chelate $\mathrm{Ca}$ from $\mathrm{CN}$ (i.e., a holding time at $80^{\circ} \mathrm{C}$ was not required to facilitate Ca chelation).

In solution, polyphosphates can undergo hydrolysis to orthophosphates, particularly at higher temperatures $\left(>60^{\circ} \mathrm{C}\right.$; Maurer-Rothmann and Scheurer, 2005). In practice, it is likely that the hydrolytic breakdown is low in most process cheese applications (Maurer-Rothmann and Scheurer, 2005). During holding of process cheese at high temperature some hydrolysis of SHMP may have occurred (Lee and Alais, 1980); however, holding time had no significant effect on the concentration of insoluble $\mathrm{P}$ in process cheese (Table 3 ). It has been claimed (Roesler, 1966) that hydrolysis also occurs in process cheese during storage. Because the process cheese samples were not analyzed until after 7 d of storage, any (possible) hydrolysis should already have occurred before testing of cheese.

Comparing the results reported by Shirashoji et al. (2006) for process cheese made with TSC to those made with SHMP in the present study, we observed that cheese made with SHMP had lower LT values at $50^{\circ} \mathrm{C}$ and lower DOF values for all experimental conditions. The experimental work for our previous study (Shirashoji et al., 2006) was actually performed around the same time period as the current study. The hardness values for process cheese made with various concentrations of TSC were much lower (range: 1,572-2,685 g; Shirashoji et al., 2006) compared with cheese made with SHMP (range: $1,892-4,490 \mathrm{~g}$ ).

\section{CONCLUSIONS}

The concentration of SHMP used as an ES in the manufacture of pasteurized process Cheddar cheese greatly affected the textural and melting properties, even when these cheeses had a similar $\mathrm{pH}$ value. The added SHMP appeared to convert the original form of $\mathrm{CCP}$ to a new type of $\mathrm{Ca}$ phosphate salt during cooking. A small quantity of SHMP $(0.25 \%)$ was not enough to efficiently disperse the CN network even with long holding times during cooking; consequently, fat was poorly emulsified and the process cheese was soft and highly meltable. Holding times increased hardness and decreased meltability. High levels of SHMP produced firm and poorly meltable cheese because CN were highly dispersed during cooking, SHMP resulted in the formation of new Ca phosphate-CN linkages, and a fine-stranded network was formed during cooling. The results of this study will assist process cheese manufacturers in understanding the role of SHMP as an ES and demonstrates the effect of ES concentration and holding time on process cheese functionality.

\section{REFERENCES}

Berger, W., H. Klostermeyer, K. Merkenich, and G. Uhlmann. 1998. Process Cheese Manufacture-A JOHA Guide. BK Guilini Chemie Gmbh \& Co. OHG, Ladenburg, Germany.

Carić, M., M. Gantar, and M. Kalab. 1985. Effect of emulsifying agents on the microstructure and other characteristics of process cheese. Food Microstruct. 4:297-312. 
Department of Health and Human Services. 2004. Food and Drugs: Code of Federal Regulations. Part 133: Cheese and Related Cheese Products. DHHS, Washington, DC.

Dimitreli, G., A. S. Thomareis, and P. G. Smith. 2005. Effect of emulsifying salts on casein peptization and apparent viscosity of processed cheese. Int. J. Food Eng. 1:1-15.

Guinee, T. P., M. Caric, and M. Kalab. 2004. Pasteurized processed cheese and substitute/imitation cheese products. Pages 349-394 in Cheese: Chemistry, Physics and Microbiology. Vol. 2. 3rd ed. P. F. Fox, ed. Elsevier, London, UK.

Gupta, S. K., C. Karahadian, and R. C. Lindsay. 1984. Effect of emulsifier salts on texture and flavor properties of processed cheeses. J. Dairy Sci. 67:764-778.

Hassan, A., M. E. Johnson, and J. A. Lucey. 2004. Changes in the proportions of soluble and insoluble calcium during the ripening of Cheddar cheese. J. Dairy Sci. 87:854-862.

IDF. 1982. Determination of total solids content of cheese and processed cheese. 4A:1982. International Dairy Federation, Brussels, Belgium.

IDF. 1986. Determination of nitrogen content (Kjeldahl method) and calculation of crude protein content. 20A:1986. International Dairy Federation, Brussels, Belgium.

Johnston, D. E., and R. J. Murphy. 1992. Effects of some calciumchelating agents on the physical properties of acid-set milk gels. J. Dairy Res. 59:197-208.

Kapoor, R., and L. Metzger. 2008. Process cheese: Scientific and technological aspects-A review. Comp. Rev. Food Sci. Food Safety 7:194-214.

Lee, B. O., and C. Alais. 1980. Étude biochimique de la fonte des fromages. II. Evolution des phosphates et des métaux. Lait 60:130-139.

Lee, B. O., D. Paquet, and C. Alais. 1986. Étude biochimique de la fonte des fromages. VI. Effet du type de sels de fonte et de la nature de la matière protéique sur la peptisation. Utilisation d'un système modèle. Lait 66:257-267.

Lu, Y., N. Shirashoji, and J. A. Lucey. 2008. Effects of $\mathrm{pH}$ on the textural properties and meltability of pasteurized process cheese made with different types of emulsifying salts. J. Food Sci. 73:363-369.

Lucey, J. A., and P. F. Fox. 1993. Importance of calcium and phosphate in cheese manufacture: A review. J. Dairy Sci. 76:1714-1724.

Lucey, J. A., C. Gorry, and P. F. Fox. 1993. Acid-base buffering properties of heated milk. Milchwissenschaft 48:438-441.

Lucey, J. A., M. E. Johnson, and D. S. Horne. 2003. Perspectives on the basis of the rheology and texture properties of cheese. J. Dairy Sci. 86:2725-2743.

Marshall, R. T. 1992. Standard Methods for the Examination of Dairy Products. 16th ed. American Public Health Association, Washington, DC.

Maurer-Rothmann, A., and G. Scheurer. 2005. Stabilization of Milk Protein Systems: A JOHA Guide. BK Giulini GmbH, Ladenburg, Germany.

Mizuno, R., and J. A. Lucey. 2005. Effects of emulsifying salts on the turbidity and calcium-phosphate-protein interactions in casein micelles. J. Dairy Sci. 88:3070-3078.
Mizuno, R., and J. A. Lucey. 2007. Properties of milk protein gels formed by phosphates. J. Dairy Sci. 90:4524-4531.

Molins, R. A. 1991. Phosphates in Food. CRC Press, Boca Raton, FL.

Montgomery, D. C. 2001. Design and Analysis of Experiments. 5th ed. John Wiley, New York, NY.

Mullen, L., and D. M. Ennis. 1979. Rotatable design in product development. Food Technol. 33:74-75, 78-80.

Mulsow, B. B., D. Jaros, and H. Rohm. 2007. Processed cheese and cheese analogues. Pages 210-235 in Structure of Dairy Products. A. Tamime, ed. Blackwell, Oxford, UK.

Muthukumarappan, K., Y.-C. Wang, and S. Gunasekaran. 1999a. Modified Schreiber test for evaluation of Mozzarella cheese meltability. J. Dairy Sci. 82:1068-1071.

Muthukumarappan, K., Y.-C. Wang, and S. Gunasekaran. 1999b. Estimating softening point of cheeses. J. Dairy Sci. 82:22802286 .

Odagiri, S., and T. A. Nickerson. 1964. Chain length determination of polyphosphate. J. Dairy Sci. 47:920-921.

Odagiri, S., and T. A. Nickerson. 1965. Complexing of calcium by hexametaphosphate, oxalate, citrate, and ethylenediaminetetraacetate in milk. II. Dialysis of milk containing complexing agents. J. Dairy Sci. 48:19-22.

Panouillé, M., T. Nicolai, and D. Durand. 2003. Heat induced aggregation and gelation of casein submicelles. Int. Dairy J. 14:297-303.

Rayan, A. A., M. Kalab, and C. A. Ernstrom. 1980. Microstructure and rheology of process cheese. Scan. Electron Microsc. III:635643.

Roesler, H. 1966. Verhalten der polyphosphate in schmelzkäse. Milchwissenschaft 21:104-107.

Shimp, L. A. 1985. Process cheese principles. Food Technol. 39:6369.

Shirashoji, N., J. J. Jaeggi, and J. A. Lucey. 2006. Effect of trisodium citrate concentration and cooking time on the physicochemical properties of pasteurized process cheese. J. Dairy Sci. 89:15-28.

Taneya, S., T. Kimura, T. Izutsu, and W. Buchheim. 1980. The submicroscopic structure of processed cheese with different melting properties. Milchwissenschaft 35:479-481.

Thomas, M. A. 1973. The Manufacture of Processed Cheese - Scientific Principles. 1st ed. New South Wales Department of Agriculture, Richmond, NSW, Australia.

Udayarajan, C. T., J. A. Lucey, and D. S. Horne. 2005. Use of Fourier transform mechanical spectroscopy to study the melting behavior of cheese. J. Texture Stud. 36:489-515.

Van Wazer, J. R., and C. F. Callis. 1958. Metal complexing by phosphates. Chem. Rev. 58:1011-1046.

Vujicic, I., J. M. deMan, and I. L. Woodrow. 1968. Interaction of polyphosphates and citrate with skim milk proteins. Can. Inst. Food Technol. J. 1:17-21.

Zehren, V. L., and D. D. Nusbaum. 2000. Processed Cheese. 2nd ed. Cheese Reporter Publishing Co. Inc., Madison, WI. 